\title{
Numerical Investigation of Source of Oriented Impact Air Flow Using Coanda Effect
}

\author{
Richard Lenhard ${ }^{1, *}$, Katarína Kaduchová ${ }^{1}$, Milan Malcho ${ }^{1}$, Peter Ďurčanský ${ }^{1}$, and Ivana \\ Klačková ${ }^{2}$ \\ ${ }^{1}$ Department of Power Engineering, Faculty of Mechanical Engineering, University of Žilina, \\ Univerzitna 1,010 26 Žilina, Slovakia
}

\begin{abstract}
The paper deals with the problem with flowing of cooling air using a phenomenon called the Coanda effect. With the help of the designed device, it is possible to generate an oriented air flow for cooling, using the Coanda effect. By means of the formed oriented air stream, it is possible to cool the pipes after heating, i.e. after welding, bending or heat treatment. The experimental part consists of designs and comparisons of design solutions of the device in the program ANSYS Fluent where the analysis of the problem of impact cooling and various device designs and measurement of actual values.
\end{abstract}

\section{Introduction}

The Coand effect is a phenomenon (Figure 1) in which a fluid stream tends to bypass a curved or flat surface and also tends to entrain a fluid of similar composition from the environment. If the stream flows along the wall and entrains the surrounding fluid with it, a vacuum is created between the wall and the jet from the nozzle and due to its action the stream is sucked to the wall.

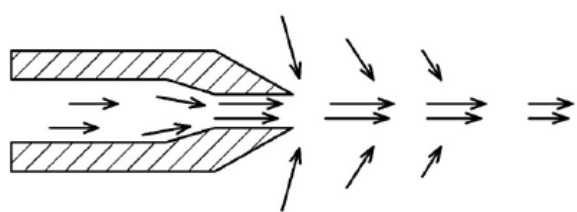

(a)

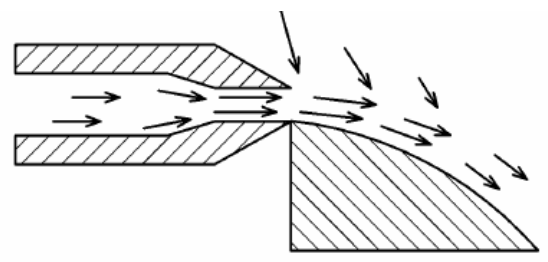

(b)

Fig. 1. Behaviour of the air stream in the open space (a) and near the adjacent surface (b) [1].

However, if the surface does not follow the outlet smoothly, or a sharp edge is created, the current does not copy this surface perfectly, but eddy currents are created in sharp places (Figure 2).

\footnotetext{
* Corresponding author: richard.lenhard@fstroj.uniza.sk
} 


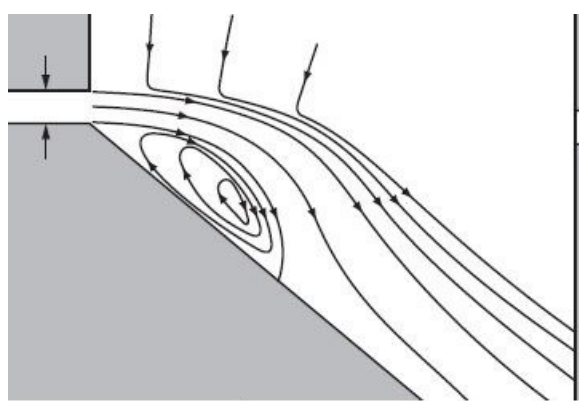

a)

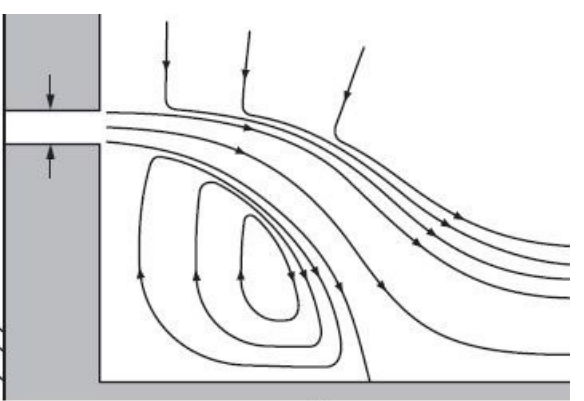

b)

Fig. 2. Turbulence occurs if the next surface does not follow the exit from the hole smoothly [2].

\section{Design of a device for generating an oriented air flow}

For numerical examination and subsequent laboratory measurement, a device for generating an oriented impact air flow with a Coanda effect was created and constructed. The device is shown in Figure 3 and Figure 4 shows a real device on which measurements were made.

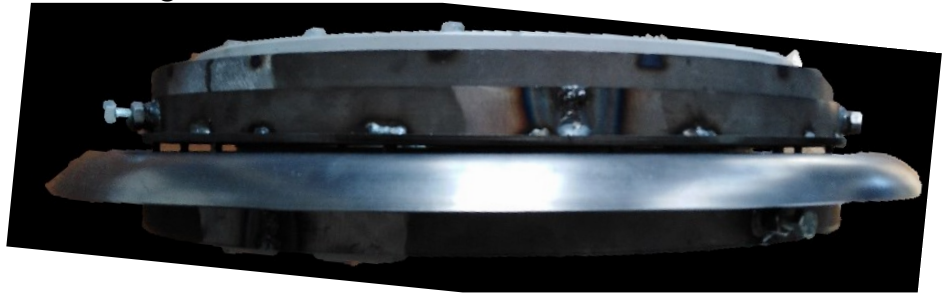

Fig. 3. Device for generating an oriented impact air flow with a Coanda effect.
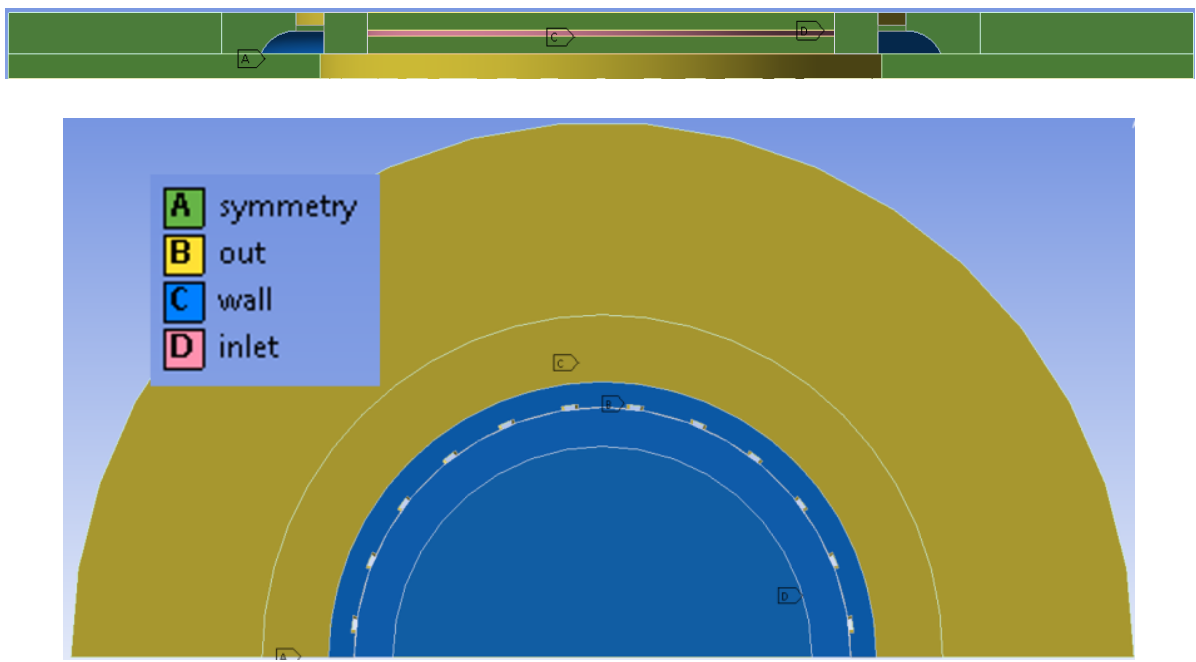

Fig. 4. 3D Model of device for generating an oriented impact air flow with a Coanda effect.

The device for generating an oriented impact flow with a Coand effect was constructed by modifying and replacing the cover of the fan HDR 60 FU (Figure 5, Table 1 in Figure 6) was installed in place of the original fan cover. 


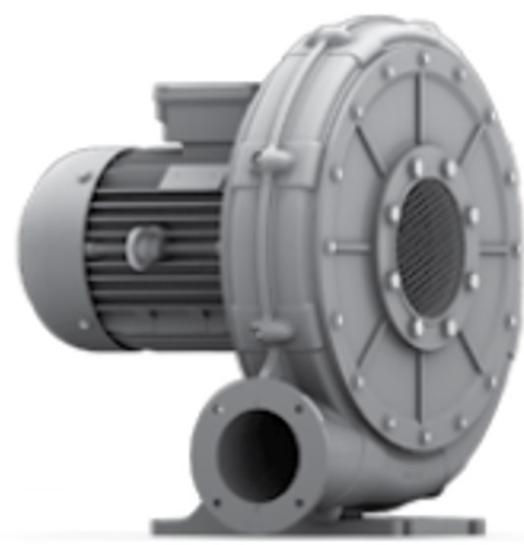

Fig. 5. Fan HRD 60 FU 105/7.5.

Table 1. Technical parameters of the fan HRD 60 FU-105/7.5.

\begin{tabular}{|c|c|c|}
\hline Parameter & Unit & Value \\
\hline Volume flow $\dot{V}$ at $0 \mathrm{~Pa}$ & $\mathrm{~m}^{3} \cdot \mathrm{min}^{-1}$ & 40 \\
\hline Pressure difference $\Delta p$ & $\mathrm{~Pa}$ & 10500 \\
\hline Supply voltage & $\mathrm{V}$ & 400 \\
\hline Frequency & $\mathrm{Hz}$ & 105 \\
\hline Rated current & $\mathrm{A}$ & 14.5 \\
\hline Rated power & $\mathrm{kW}$ & 7.50 \\
\hline Operating speed & $\mathrm{min}^{-1}$ & 6235 \\
\hline Weight & $\mathrm{kg}$ & 50 \\
\hline The price & $€$ & 1843.20 \\
\hline
\end{tabular}

Compressed air could be generated through the gap created by the newly modified fan cover. After passing the air through the gaps, which behaved like a nozzle, a Coand effect was created. This experimental device was controlled by a frequency converter ACS 310$03 \mathrm{E}$ by means of which it was possible to change the fan power. The experimental device was connected according to the wiring diagram Figure 6. 


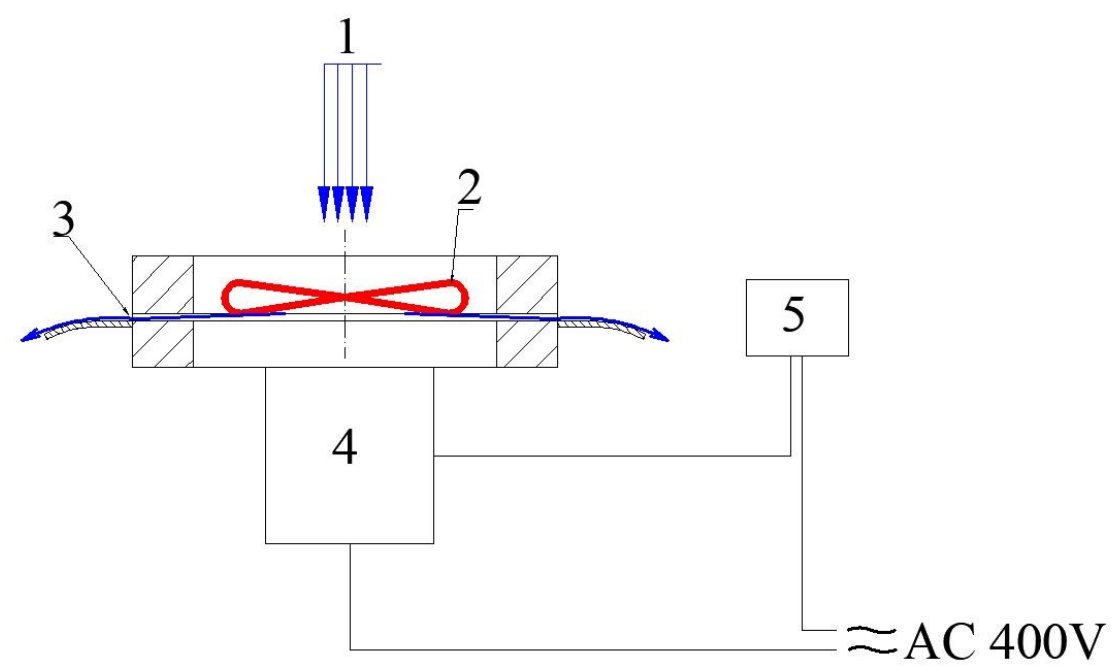

Fig. 6. Simple wiring diagram, 1 - air supply, 2 - fan, 3 - air exiting through the nozzle, 4 - fan drive, 5 - frequency converter.

\section{Numerical investigation of impact air flow with Coand effect}

\subsection{Numerical simulation of Coand effect}

For the purpose of performing a numerical simulation, a 2D simplified model was created, which is based on the original geometric design shown in Figure 7. The simulations were performed in the Ansys Fluent program in which several proposed variants were simulated. The simulations were performed with a change in the width of the nozzle (a gap was created in the fan cover), its width was $5 \mathrm{~mm}, 3 \mathrm{~mm}$ and $1 \mathrm{~mm}$. Each nozzle width was also simulated with a change in fan frequency of $40 \mathrm{~Hz}, 50 \mathrm{~Hz}$ and $60 \mathrm{~Hz}$. The result of the simulation was the shape and speed of the air generated by the fan for each variant.

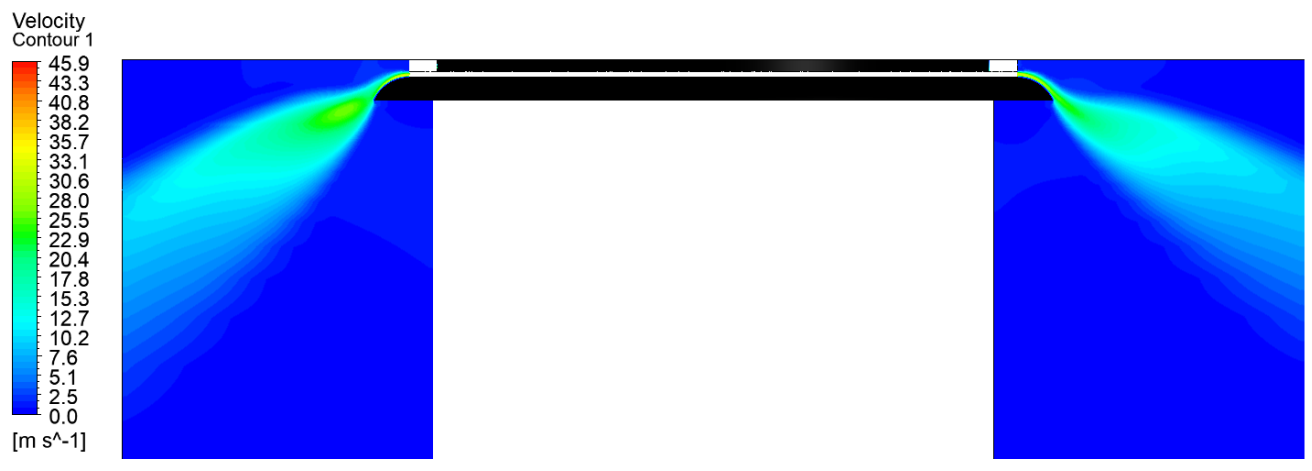

Fig. 7. Demonstration with numerical simulation of Coand effect.

\subsection{Measurement of air shape and velocity}

The measurement was performed using a propeller anemometer KIMO AMI 310 (Figure 8) with which we measured the velocity of the flowing air at various points around the outlet of the fan nozzle. A grid was formed (Figure 11), and the horizontal and vertical velocities 
of the flowing air were measured at its points by applying an anemometer. The vector product then gave the total velocity at this point. From the zero point, which was located at the mouth of the nozzle, we graded the reference points at distances of $0.1 \mathrm{~m}$. The reference points were determined by visualizing the air flow (Figure 9), using a smoke machine that was connected to draw air into the fan.

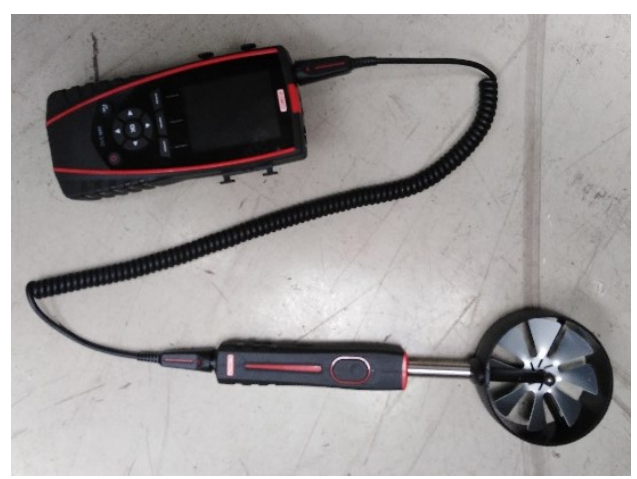

Fig. 8. Multifunction measuring device KIMO AMI 310 with propeller measuring probe $\varnothing 100 \mathrm{~mm}$.

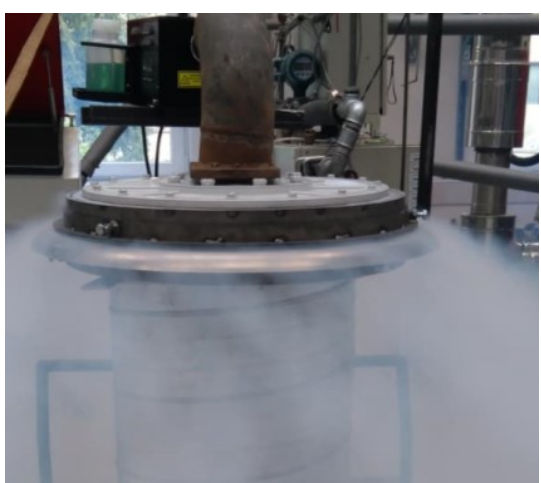

Fig. 9. Visualization of air flow from measuring.

The measurement was performed with predetermined variants with which it was tied in numerical simulations.

\section{Comparison of measurement results and numerical simulation}

To set the nozzle width $5 \mathrm{~mm}$ and frequency $40 \mathrm{~Hz}$ :

Table 2. Measured air flow velocities at individual grid points, nozzle width $5 \mathrm{~mm}$, frequency $40 \mathrm{~Hz}$.

\begin{tabular}{|c|c|c|c|c|}
\hline \multicolumn{5}{|c|}{ Measured velocity values $\left(\mathbf{m . s}^{\mathbf{- 1}}\right)$} \\
\hline 40 Hz, 5 mm \\
\hline y 0 & 3.86 & 0.81 & 0.43 & 0.00 \\
\hline $\mathbf{y}-\mathbf{1 0}$ & 3.86 & 4.27 & 3.03 & 0.45 \\
\hline $\mathbf{y ~ - 2 0}$ & 0.76 & 1.83 & 3.04 & 3.53 \\
\hline $\mathbf{y ~ - 3 0}$ & 0.60 & 0.40 & 0.67 & 2.19 \\
\hline
\end{tabular}

Table 3. Air flow velocities at grid points in ANSYS, nozzle width $5 \mathrm{~mm}$, frequency $40 \mathrm{~Hz}$.

\begin{tabular}{|c|c|c|c|c|}
\hline \multicolumn{5}{|c|}{ Velocity from ANSYS (m.s $\left.\mathbf{~}^{-1}\right)$} \\
\hline 40 Hz, 5 mm point & $\mathrm{x} 10$ & $\mathrm{x} 20$ & $\mathrm{x} 30$ & $\mathrm{x} 40$ \\
\hline $\mathbf{y ~ 0}$ & 2.95 & 1.75 & 0.65 & 0.25 \\
\hline $\mathbf{y}$-10 & 1.74 & 4.41 & 0.69 & 0.41 \\
\hline $\mathbf{y ~ - 2 0}$ & 1.99 & 4.77 & 5.13 & 1.34 \\
\hline $\mathbf{y ~ - 3 0}$ & 1.21 & 2.68 & 9.70 & 2.98 \\
\hline
\end{tabular}

The following figures show the results of the airflow trajectories from the measurement and numerical simulation from the ANSYS Fluent program with frequency $40 \mathrm{~Hz}$ (Figure 10 and Figure 11) for their mutual comparison. From the results, it can be concluded that the simulation was able to obtain similar results as obtained in the measurement. 


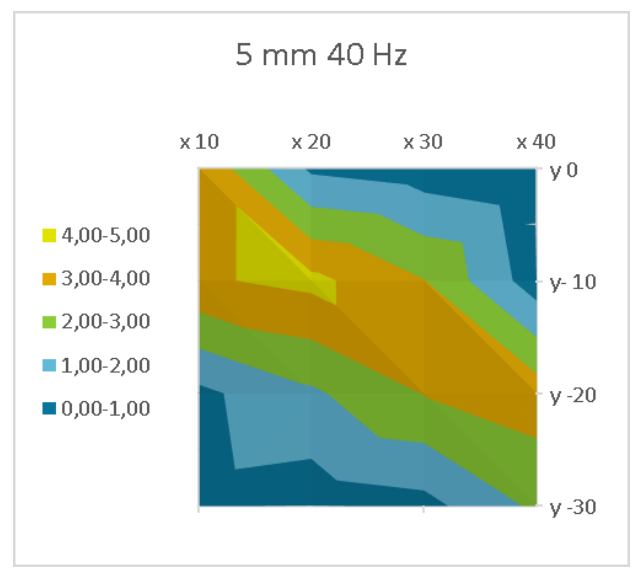

Fig. 10. Visualization of air flow according to measured velocity, nozzle width $5 \mathrm{~mm}$, frequency $40 \mathrm{~Hz}$.

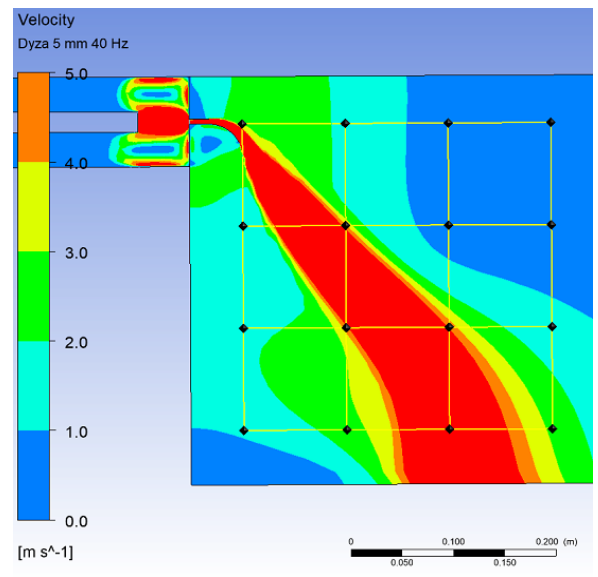

Fig. 11. Visualization of air flow in ANSYS program, nozzle width $5 \mathrm{~mm}$, frequency $40 \mathrm{~Hz}$.

For setting the nozzle width to $5 \mathrm{~mm}$ and the frequency $50 \mathrm{~Hz}$ :

Table 4. Measured air flow velocities at individual grid points, nozzle width $5 \mathrm{~mm}$, frequency $50 \mathrm{~Hz}$.

\begin{tabular}{|c|c|c|c|c|}
\hline \multicolumn{5}{|c|}{ Measured velocity values (m.s $\left.\mathbf{~}^{-1}\right)$} \\
\hline \multicolumn{5}{|c|}{$\mathbf{5 0 ~ H z}, \mathbf{5} \mathbf{~ m m}$} \\
\hline ref. point & x 10 & x 20 & x 30 & x 40 \\
\hline y 0 & 6.81 & 0.76 & 0.63 & 0.52 \\
\hline y- 10 & 5.58 & 6.27 & 1.84 & 0.64 \\
\hline y -20 & 0.98 & 1.56 & 4.61 & 2.24 \\
\hline y -30 & 1.00 & 0.60 & 3.97 & 3.99 \\
\hline
\end{tabular}

Table 5. Air flow velocities at grid points in ANSYS, nozzle width $5 \mathrm{~mm}$, frequency $50 \mathrm{~Hz}$.

\begin{tabular}{|c|c|c|c|c|}
\hline \multicolumn{5}{|c|}{ Velocity from ANSYS (m.s $\left.{ }^{-1}\right)$} \\
\hline \multicolumn{5}{|c|}{$50 ~ \mathbf{~ H z}, \mathbf{~ m m}$} \\
\hline ref. point & x 10 & x 20 & x 30 & x 40 \\
\hline y 0 & 2.89 & 2.04 & 0.92 & 0.40 \\
\hline y- 10 & 1.70 & 4.18 & 1.03 & 0.54 \\
\hline y -20 & 1.62 & 5.69 & 4.60 & 1.42 \\
\hline y -30 & 0.63 & 1.99 & 11.00 & 4.10 \\
\hline
\end{tabular}

In the following figures (Figure 12 and Figure 13) we see a comparison of the air flow trajectories in the ANSYS Fluent program and the trajectory according to the measured values with frequency $50 \mathrm{~Hz}$. From the results, it can be concluded that the simulation was able to obtain similar results as obtained in the measurement 


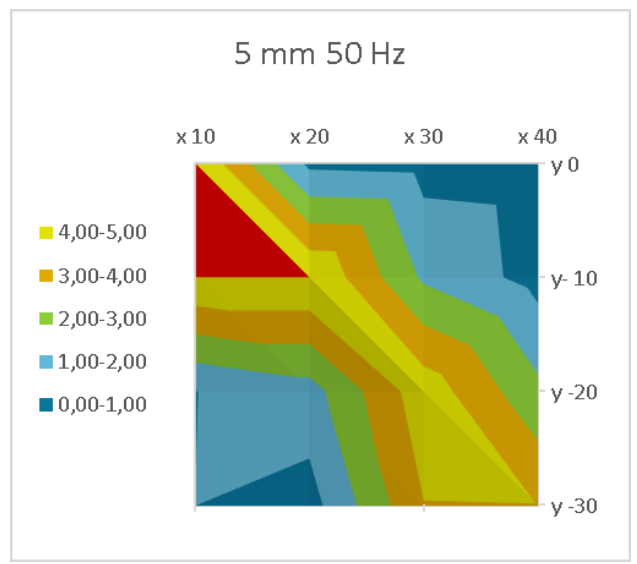

Fig. 12. V Visualization of air flow according to measured velocity, nozzle width $5 \mathrm{~mm}$, frequency $50 \mathrm{~Hz}$.

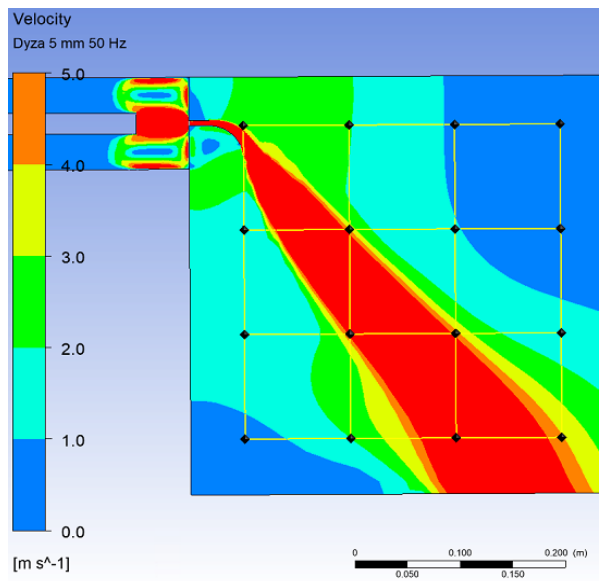

Fig. 13. Visualization of air flow in ANSYS program, nozzle width $5 \mathrm{~mm}$, frequency $50 \mathrm{~Hz}$.

For setting the nozzle width to $5 \mathrm{~mm}$ and the frequency $60 \mathrm{~Hz}$ :

Table 6. Measured air flow velocities at individual grid points, nozzle width $5 \mathrm{~mm}$, frequency $60 \mathrm{~Hz}$.

\begin{tabular}{|c|c|c|c|c|}
\hline \multicolumn{5}{|c|}{ Measured velocity values (m.s ${ }^{-1}$ ) } \\
\hline \multicolumn{5}{|c|}{$\mathbf{5}$ mm } \\
\hline ref. point & x 10 & x 20 & x 30 & x 40 \\
\hline y 0 & 8.82 & 1.32 & 0.69 & 0.52 \\
\hline $\mathbf{y}-\mathbf{1 0}$ & 3.31 & 8.42 & 3.34 & 0.63 \\
\hline $\mathbf{y}-\mathbf{2 0}$ & 0.95 & 3.86 & 6.16 & 5.26 \\
\hline $\mathbf{y}-\mathbf{3 0}$ & 1.15 & 0.78 & 6.00 & 4.15 \\
\hline
\end{tabular}

Table 7. Air flow velocities at grid points in ANSYS, nozzle width $5 \mathrm{~mm}$, frequency $\mathrm{Hz}$.

\begin{tabular}{|c|c|c|c|c|}
\hline \multicolumn{5}{|c|}{ Velocity from ANSYS (m.s $\left.{ }^{-1}\right)$} \\
\hline \multicolumn{5}{|c|}{$\mathbf{6 0 ~ H z , ~ 5 ~ m m ~}$} \\
\hline ref. point & x 10 & x 20 & x 30 & x 40 \\
\hline y 0 & 2.86 & 2.23 & 1.11 & 0.48 \\
\hline $\mathbf{y - ~ 1 0}$ & 1.74 & 3.99 & 1.25 & 0.64 \\
\hline $\mathbf{y ~ - 2 0}$ & 1.38 & 7.11 & 3.71 & 1.35 \\
\hline $\mathbf{y}-\mathbf{3 0}$ & 0.50 & 1.67 & 12.29 & 3.95 \\
\hline
\end{tabular}

The following figures (Figure 14 and Figure 15) show a comparison of the airflow trajectories in the ANSYS Fluent program and the trajectory according to the measured values with frequency $60 \mathrm{~Hz}$. From the results, it can be concluded that the simulation was able to obtain similar results as obtained in the measurement. 


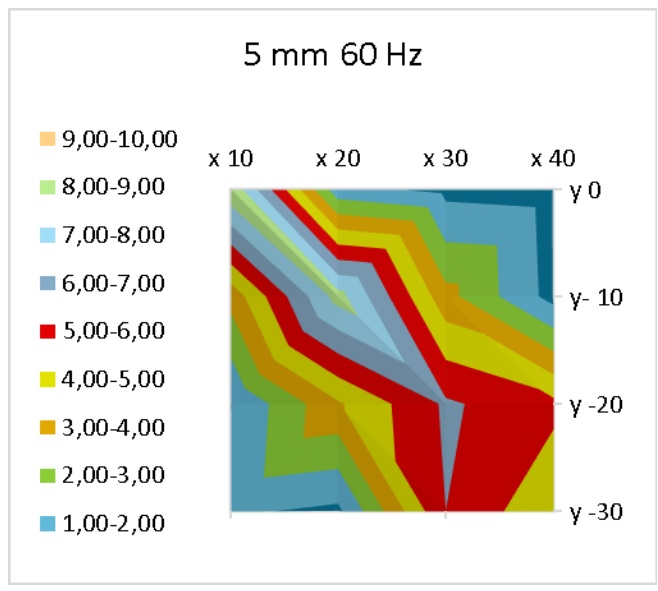

Fig. 14. Visualization of air flow according to measured velocity, nozzle width $5 \mathrm{~mm}$, frequency $60 \mathrm{~Hz}$.

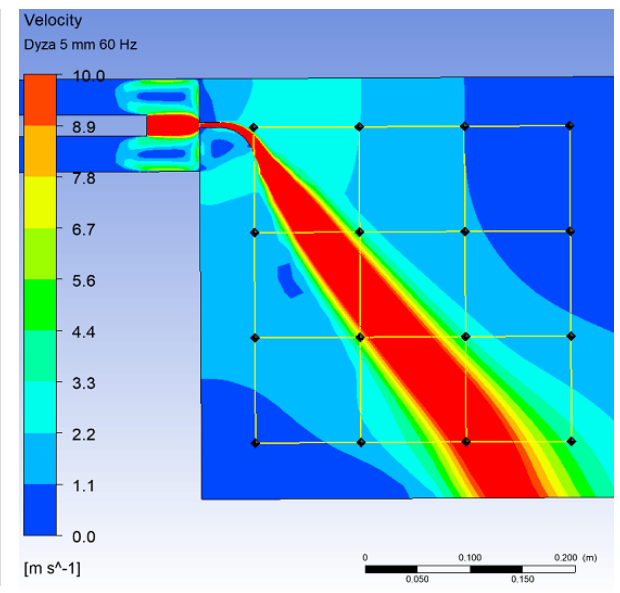

Fig. 15. Visualization of air flow in ANSYS program, nozzle width $5 \mathrm{~mm}$, frequency 60 $\mathrm{Hz}$.

Evaluation of results for a nozzle with a width of $5 \mathrm{~mm}$ :

As Table 8 shows, at a nozzle width of $5 \mathrm{~mm}$ and a fan frequency of $60 \mathrm{~Hz}$, we reached a maximum velocity of $57.28 \mathrm{~m} \cdot \mathrm{s}^{-1}$ at the outlet of the chamber, which corresponds to a mass flow of $14.5 \mathrm{~kg} . \mathrm{s}^{-1}$ (Table 9). However, the output from the ANSYS program showed us a speed of $38.96 \mathrm{~m} \cdot \mathrm{s}^{-1}$. The real airflow had a larger range than the program, in which it was thinner and the velocity was more concentrated in the middle of the flow. Compared to the output from the program, the real current led more horizontally, especially towards the end of the observed trajectory.

Table 8. Maximum outlet velocity from a $5 \mathrm{~mm}$ wide nozzle at different frequencies.

\begin{tabular}{|c|c|c|c|}
\hline \multicolumn{4}{|c|}{ Comparison of nozzle output velocity $\left({\mathrm{m} . \mathbf{s}^{-1}}^{-1}\right)$} \\
\hline \multicolumn{4}{|c|}{ Nozzle width $\mathbf{5} \mathbf{~ m m}$} \\
$\begin{array}{c}\text { Total transport } \\
\text { pressure } \boldsymbol{\Delta p}(\mathrm{Pa})\end{array}$ & Frequency (Hz) & $\begin{array}{c}\text { ANSYS } \\
\text { Fluent }\end{array}$ & Calculated \\
\hline 1640 & 40 & 35.44 & 52.18 \\
\hline 1850 & 50 & 37.66 & 55.39 \\
\hline 1980 & 60 & 38.96 & 57.28 \\
\hline
\end{tabular}


Table 9. Maximum possible flow at a given flow rate for the nozzle width $5 \mathrm{~mm}$.

\begin{tabular}{|c|c|c|}
\hline \multicolumn{3}{|c|}{ Nozzle width 5 mm } \\
\hline $\begin{array}{c}\text { Frequency } \\
\text { (Hz) }\end{array}$ & $\begin{array}{c}\text { Calculated maximum } \\
\text { velocity }\left(\mathbf{m . s}^{-1}\right)\end{array}$ & Maximum mass flow (kg.s $\left.{ }^{-1}\right)$ \\
\hline 40 & 52.18 & 13.21 \\
\hline 50 & 55.39 & 14.02 \\
\hline 60 & 57.28 & 14.50 \\
\hline
\end{tabular}

\section{Conclusion}

The presented paper deals with the phenomenon called the Coanda effect and with the oriented impact airflow. The content also includes the design of the device and verification of the properties of the flow field as a source of oriented air flow. The model of the device for generating the air flow was created in the ANSYS Fluent program where a numerical simulation was performed, which could then be compared with the measurement results. The measurement itself was performed at nozzle settings with widths of $5 \mathrm{~mm}, 3 \mathrm{~mm}$ and $1 \mathrm{~mm}$, at frequencies set on the fan $40 \mathrm{~Hz}, 50 \mathrm{~Hz}$ and $60 \mathrm{~Hz}$. The real properties were verified only for the maximum output velocity from the chamber $57.28 \mathrm{~m} \cdot \mathrm{s}^{-1}$, which was achieved with a $5 \mathrm{~mm}$ nozzle with a frequency of $60 \mathrm{~Hz}$.

During the measurement itself, certain shortcomings of the construction were found, such as the attachment of the disk forming the upper edge of the nozzle, which by its gripping principle prevented a firm grip without subsequent deformation of the disk. The tightening screws crossed the disc around the circumference and thus made it difficult to adjust the width of the nozzle. Another disadvantage was that when the screws were "locked" against the side of the fan, gaps were created between the disc and this side through which air escaped, which could affect the current field. The solution would be to produce a disc with a fine internal overlap so that this disc charges on the sidewall. Alternatively, if it is not necessary to adjust the width of the nozzle, this disc could be welded and thoroughly sealed circumferentially.

The obtained results can be used in further investigation of the possibility of cooling using the Coand effect. When comparing the obtained results, it can be said that the model created in the numerical simulation corresponds well with the measurement results and it is possible to consider it further in further research of the possibility of cooling using the Coand effect.

Acknowledgements: This work was founded by projects KEGA 063ŽU-4/2018 The storage of hydrocarbon gases in hydrate structures as an alternative method of energy accumulation.

\section{References}

1. O. Crivoi, I. Doroftei, IOP Conference Series: Materials Science and Engineering, 147, (2016)

2. V. Sidiropoulos, J. Vlachopoulos, International Polymer Processing Journal of the Polymer Processing Society, (2000) 
3. L. J. Orman, N. Radek, A. Kapjor, Surface Treatment Technologies for Boiling Heat Transfer augmentation, Terotechnology, 2017, Materials Research Proceedings, 216219, 5 (2018)

4. P. Stephan, VDI Heat Atlas (2010)

5. J. Ondruskova, T. Luks and J. Horsky, EPJ Web of Conferences 25, 01063 (2012)

6. R. Pastircak, J. Scury, M. Bruna, et al., Archives of foundry engineering, 17 (2017)

7. Z. Vaszi, J. Šváb, A. Varga, G. Jablonský, J. Kizek, L. Lazić, The holistic approach to environment. 1, 3 (2011)

8. J. Soukup, B. Skocilasova, J. Skocilas, Jan; et al., AIP Conference Proceedings 2118, 030041 (2019)

9. R. Nosek, M. Holubcik, Energy properties of air dry firewood, Acta Facultitas Xylologiae Zvolen, 58, 1, pp: 105-112 (2016) doi: 10.17423/afx.2016.58.1.12

10. M. Rimar, A. Kulikov, M. Fedak, et al., Em journal-technology education management informatics 7, (2018) 